\title{
Resource Optimization of Construction Project Using Primavera P6
}

\author{
Vignesh $\mathrm{V}^{1}$ \\ B.E., Thiagarajar College of Engineering, Department of civil Engineering, Madurai-625015, India ${ }^{1}$
}

\begin{abstract}
Construction projects are unique in nature, having their own difficulties, uncertainties and risks, posing never-ending questions concerning the resources and costs. There is always a conflict between 'how much it will cost?' and 'where to raise the finances from?'. The success of a project depends upon the efficiency with which the project management gets the work done by utilizing the planned resources of men, materials, machinery, money and time.. In large scale projects, preparing an accurate and workable plan is very difficult. Resources are required to carry out specific tasks in a project, but the availability of resources within a given firm is always limited. While preparing the schedule structure, the Project Manager might schedule certain tasks in parallel. In such cases it might be possible that the same resource is being used in both the parallel tasks, while its availability is limited. This paper emphasises how the Project Manager could resolve such conflicts by using Resource Balancing in modern softwares such as Primavera (P6) R8.3, to reduce laborious computations. In this paper, the Resource Balancing techniques namely smoothing \& leveling have been investigated in detail. This paper uses a case study in order to portray how Resource Balancing could be done using Primavera 66 and its effects are on the duration and cost of the entire project.
\end{abstract}

Keywords: Critical Path Method, Primavera, Resource Balancing, Smoothing, Leveling.

\subsection{Resource Balancing}

\section{Introduction}

Resource Balancing is a process that gives an idea about availability of sufficient resources to perform the activities in the chosen project according to the plan. During resource balancing, an activity is only scheduled to occur when its resource demands are met. To accomplish this, tasks may be delayed to resolve conflicts related to resource availability. The resources in a project can be smoothened and also levelled.

\subsection{Resource Levelling}

The network technique focuses on time element and assumes that unlimited resources are available for assigning to the activities to satisfy the time schedule.But when resources are limited, the "critical path" and "slack" lose their significance. Activity may be delayed due to non-availability of resources as well as due to change in the sequence of tasks. The process of distribution of available resources to meet the objectives of various activities constituting a project is called "Resource Allocation" or "Resource Loading". This is done in a way so that the project completion schedule is least affected. The act of taking a project with people assigned to a bunch of tasks and making it so that they don't have to work overtime is called Resource Levelling.

Step 1: Allocate resources serially in time. That is, start with the first time-period (e.g. $1^{\text {st }}$ day, $1^{\text {st }}$ week etc.) and schedule all activities possible with the available resources. Then move on to the next time-period and repeat the same.

Step 2: When several activities are assigned for the same resources, give preference to the activities with least slack.

Step 3: Reschedule non-critical activities if possible so as to free resources for the critical activities.

In this process, originally non-critical activities may become critical and the completion time of the project may be stretched. Critical path, i.e. a path comprising of activities with zero slack may not remain "critical" in strict sense of the term. After completing resource leveling, resource smoothing may be carried out for further optimization of the problem. Resource smoothing does not change the duration of the project; it only works on the non critical activities.

\subsection{Types of Resource leveling}

\subsubsection{Delaying the task}

If a resource is not available for a given task, the given task would be delayed. The software would first perform the activity which is given higher priority in the software. By default the softwares give the same priority to all tasks. The priority for all the tasks may be assigned at the time of preparation of the schedule structure. To control which tasks take precedence over other tasks, user can set project priorities, so that if the user is working with a common pool of resources among multiple projects, the right projects and tasks take precedence. 


\subsubsection{Splitting}

Certain types of work may be interrupted in between execution, instead of listing these tasks as two separate activities; the given task may be split in two or more segments. But it is a well-known fact that when resources have to switch tasks or projects mid-stream, they lose time as they have to re-orient themselves to the work.

\subsubsection{Overtime:}

The given resources may have to work overtime in order to complete the given work. They are paid more wages than that for the standard work hours which is specified by Work Overtime factor. This can level the resources only up to a certain extent and not beyond that.

\subsection{Levelling:}

This may be done in two ways, that is automatic levelling or manual levelling. Manual Leveling is always preferred over automatic leveling as it gives much more control in decision making. Automatic leveling gives no control to the user and the software levels all the resources. The only really useful method is the manual resource levelling. It is just impossible for an application to take into account all the possible conditions and restrictions from the real world projects in order to produce good results through an automatic levelling. Just in case the levelling is done automatically, the project manager needs to review the schedule in detail to ensure the automatic schedule makes sense.

\subsubsection{Process of Resource Leveling:}

1. Develop Work Breakdown Structure (WBS) to establish work elements constituting the project.

2. Determine inter-dependency among various work elements or activities/tasks and accordingly define logical sequence of the activities.

3. Quantify each work element in terms of time/other resources requirements.

4. Find out constraints, if any, external (e.g. government policies, law and order problem, inadequacies of infrastructure,etc.) andinternal (e.g. poor choice of site, inadequacies in agreement with collaborators/ consultants, technical incompetence, etc.).

5. Review the work elements, their inter-dependencies and quantification, in the light of the identified constraints.

6. Develop a flow path of activities, satisfying the logic of interdependency of activities and constraints. Develop a time schedule of activities satisfying the logic of the flow path and time duration of the activities.

7. Check for any resource over-allocation either in the Resource Graph (Figure 5 \& Figure 7).

8. Any Over-allocations are indicated in red by the given software.

9. Level all the given resources to develop a revised schedule by using the leveling tool. The over-allocations indicated in red will no longer be seen on the software once this is done (Figure $6 \&$ Figure 8).

The Process of Resource Levelling has been depicted below (Figure 1).

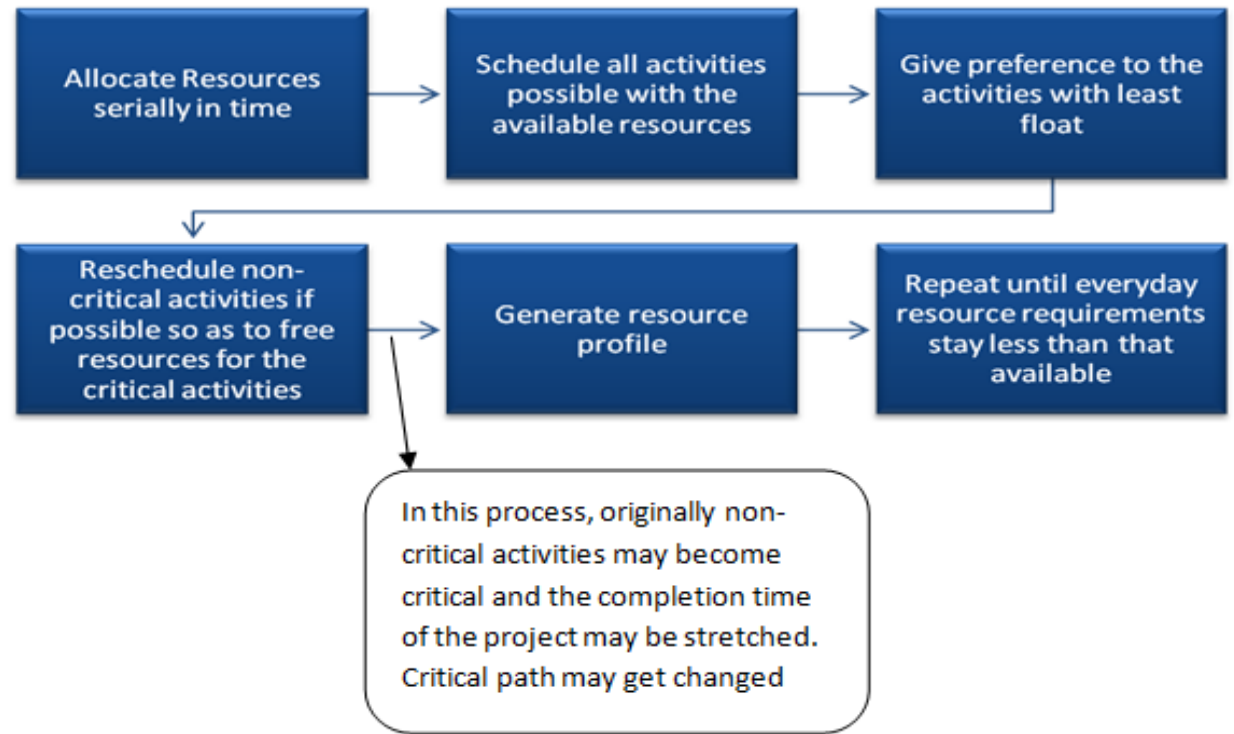

Figure 1 - Process of Resource Levelling 


\subsection{Resource Smoothing:}

The PMBOK defines resource smoothing as, "A technique that adjusts the activities of a schedule model such that the requirements for resources on the project do not exceed certain predefined limits."It means we want to have a constant resource usage (resource profile) over time. The reasons are obvious. When there are high fluctuations in demand of the resources during a project, project cost may increase because you may have to hire them to cover the peaks in the resource profile. Also, when there are valleys (or troughs) in the resource profile, resources will remain idle during those periods while still being paid. Both situations are undesirable. Hence smoothing is needed and applied. The name "smoothing" comes from the fact that the peaks and the valleys in the resource usage profile are smoothed out.In resource smoothing, the requirement of the resources don't exceed certain predefined limits. The critical path won't be touched to ensure that the duration remains unchanged. It means we can adjust the resource profiles within the available float (or slack) for the given activities. If the floats are in short supply for the activities, then we may not be able to optimize all the resources.

\subsubsection{Process of Resource smoothing:}

The Process of Resource smoothing has been depicted below (Figure 2)



Figure 2 - Process of Resource Smoothing

\section{Case Study}

This is a cancer centre construction project, where the schedule structure is prepared initially without considering any shortage in resources. Once the initial schedule is prepared, over allocations are checked for the resources. Resource over-allocation is resolved by carrying out automatic levelling on the softwares. Initially Resource smoothing operation was performed and with that data as a base resource leveling was again performed.While carrying out resource levelling, some non critical activities turn into critical activities. The critical activities are given higher preference over the non critical activities.The following are the labour resources constraints which have been used on the site and are considered for resource balancing in this case study of the cancer centre project.

Table -1 Labour constraints

\begin{tabular}{|l|l|l|}
\hline S.no & Labour & Availability/day \\
\hline 1. & mason $1^{\text {st }}$ class & 15 \\
\hline 2. & mason $2^{\text {nd }}$ class & 15 \\
\hline 3. & mazdoor $1^{\text {st }}$ cat & 30 \\
\hline 4. & mazdoor $2^{\text {nd }}$ cat & 30 \\
\hline 5. & ${\text { carpenter } 1^{\text {st }} \text { class }}^{\text {nd }}$ class & 20 \\
\hline 6. & ${\text { carpenter } 2^{\text {ns }}}^{\text {na }}$ class & 10 \\
\hline 7. & fitter $1^{\text {nd }}$ class & 20 \\
\hline 8. & fitter $^{\text {st }}$ class & 20 \\
\hline 9. & stone cutter $1^{\text {st }}$ class & 3 \\
\hline 10. & plumber $2^{\text {nd }}$ class & 10 \\
\hline 11. & plumber & 10 \\
\hline 12. & painter $1^{\text {st }}$ class & 10 \\
\hline 13. & painter $2^{\text {nd }}$ class & 10 \\
\hline
\end{tabular}


Having understood the need for managing the resources involved in the project from the schedule created initially the process of resource smoothing was planned to be carried out without considering the constraint posed on the availability of the resources ensuring that the end date of the project remains unaffected. As the first step for smoothing resources, the non-critical activities were identified and their float values were noted. Accordingly they were moved along the project timeline so that, the resources utilization can be focused towards the critical activities. Meanwhile, it has to be ensured that these originally non-critical activities after pushing along the timeline, don't become critical as the float is being used up in the process. In Primavera P6 R8.3, the process is rather simple, when the checkbox 'Level resource only within activity total float' is checked in the 'Level Resource'dialog box. On doing so, we would be able to generate the resource profile. The process is done until the most satisfactory profile is obtained.A snapshot of the 'Level Resources'dialog box is shown in Figure 3.

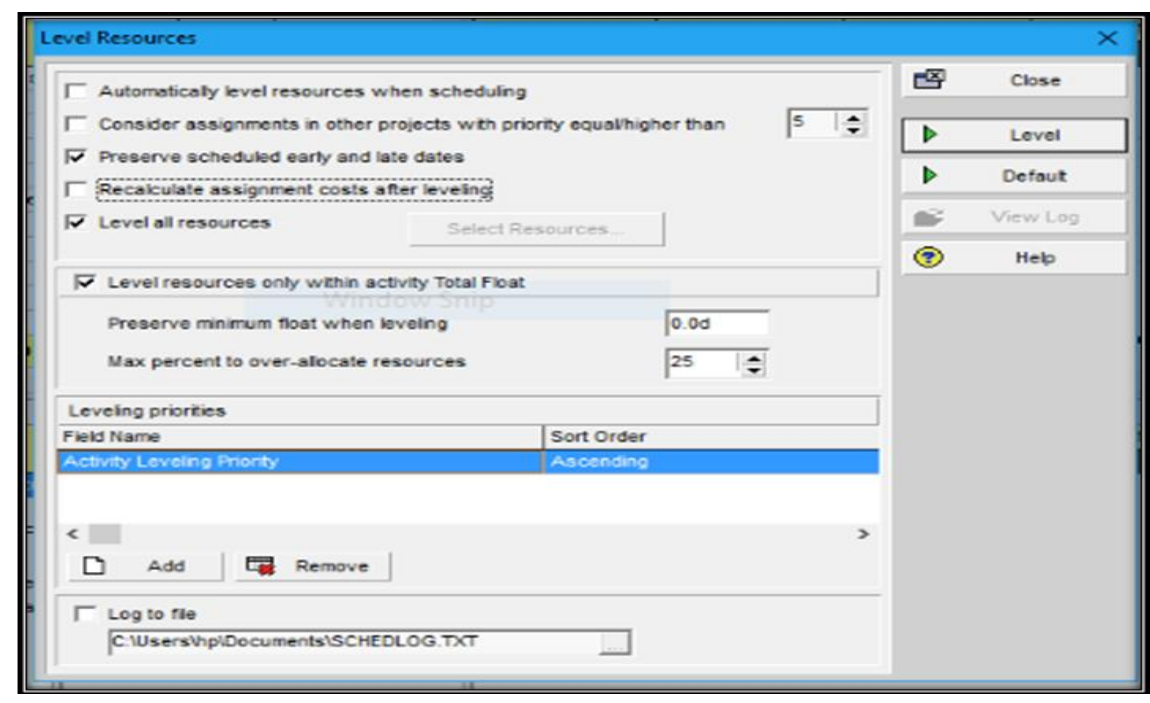

Figure 3- Level resources dialogue box for smoothing operation

After smoothing process is complete, the impact it has got on the project cost is evaluated. Resource smoothing having been carried out for the project and its impact on the project cost been analyzed, has given a better scope for proper management of the resources, which in deed has given better scope to establish control over the entire project. However, resource smoothing assumes that there are surplus resources available, which isn't the scenario under practical conditions. There is always a constraint on the availability of resources ( i.e.,the supply doesn't meet the demand ) under most situations. Thus in order to take this crucial factor into consideration in the management of resources, the process of resource leveling comes in handy, providing better means for managing the resources. In resource leveling, since there is only limited supply, under worst cases, the critical path gets affected, resulting in an increase in the project duration. However, in situations where there the supply of resources is limited, leveling proves to be advantageous by reducing the idling of resources that constitute the project. In addtition, the wastage in project cost due to idling can be effectively reduced when leveling process has been carried out. Primavera P6 aids in leveling of resources, in which only the limiting value of individual resource has to be provided for the leveling to be done. In case of leveling, the 'Level resources only within activity total float' is unchecked in the 'Level Resources' dialog box, so that when any critical activity being affected, results in an alteration of the project duration. A snapshot of the dialog box is shown in figure 4. 


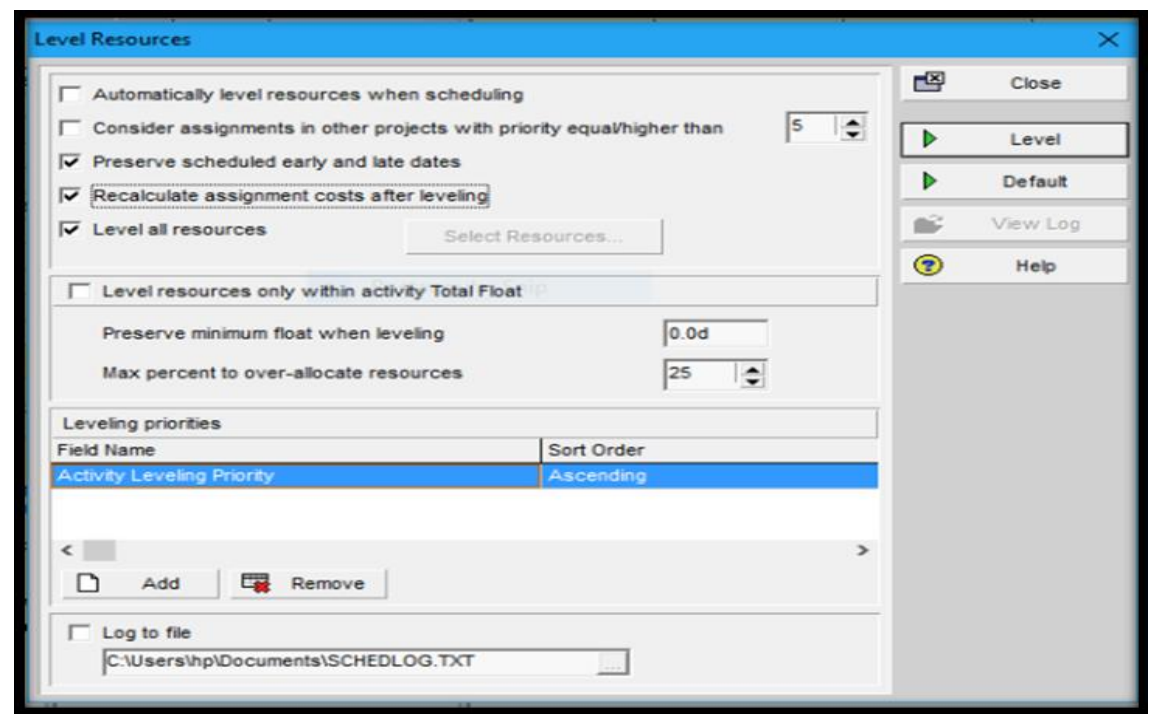

Figure 4- Level resources dialogue box for leveling operation

The resource profile is then generated. The impact of smoothing and leveling of individual resources on the project duration and the project cost are analysed, which are presented in detail in the Results and Discussion section. The wastage reduction, leading to reduction in idling of resources after leveling and the savings in work in terms of man days have been computed and represented in terms of percentage wastage.

\section{Results Of Case Study}

Owing to the crisis which was identified as a result of scheduling the project, Resource Balancing was adopted to be applied to the project, so that there is better control on the project cost and project duration by resolving the resource conflicts. As an initial attempt to establish control over the project cost from not reaching a drastically higher value, Resource Smoothing was performed. In Resource Smoothing, there is a constraint on the total project duration that it shouldn't be affected, while it assumes that there are infinite resources available. The Resource Smoothing technique, after being applied to the project, yielded with a reduction in the total project cost by Rs.4,26,157, which is about $1.02 \%$ of the projected project cost. Hence, from the results of Resource smoothing, it was understood that optimizing of the way the resources constituting the project are handled, would pave way for a reduction of the total project cost. However as resource smoothing works with an assumption that resources are available in plenty at any point of time .which is actually unrealistic with the practical scenario. To overcome this limitation of smoothing of resources, another more realistic method called Resource Leveling, was adopted to optimize resource allocation.The application of Resource Leveling to the project, gave more realistic results , offering a better insight into idling of resources and the wastage of cost owing to this idling. After leveling the resources, the peak demand for almost every resource came down, resulting in less idling of the resources contributing the project. This also leads to a reduction in the project cost incurred due to idle resources. Figures $5 \&$ 6 shows the resource histogram generated using Primavera P6 R8.3 for Mazdoor category 1, before and after leveling operation has been carried out.

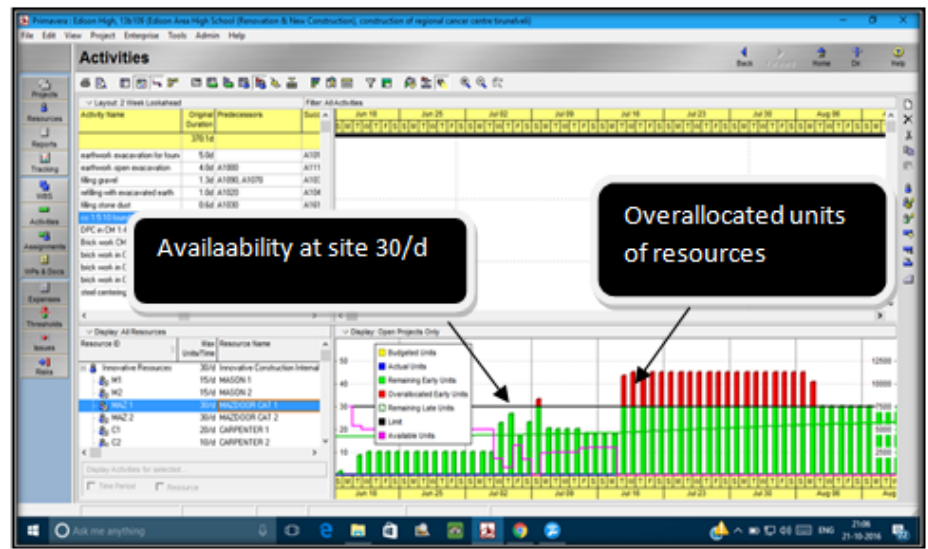

Figure 5 -Resource Histogram for Mazdoor category -1 (Before leveling) 
The histogram shown above gives the information about the quantity of Mazdoor category 1 the contractor could afford to carry out the work. But it could also be seen from the red bars in the histogram, showing need for over allocation in order to complete the project within projected duration. But, as these many quantity of mazdoor couldn't be possibly hired to work, allocation needs to be optimized to the maximum possible extent so that, idling of the mazdoor category -1 is highly minimized. However, due to constraint posed on mazdoor availability, even after leveling, some critical activities couldn't be completed as planned. Thus as the critical path tend to get affected in this more realistic scenario, there is a considerable extension of the project duration. The Snippet of Mazdoor category-1 resource histogram after leveling from primavera 66 software, has been represented below in figure 6 .

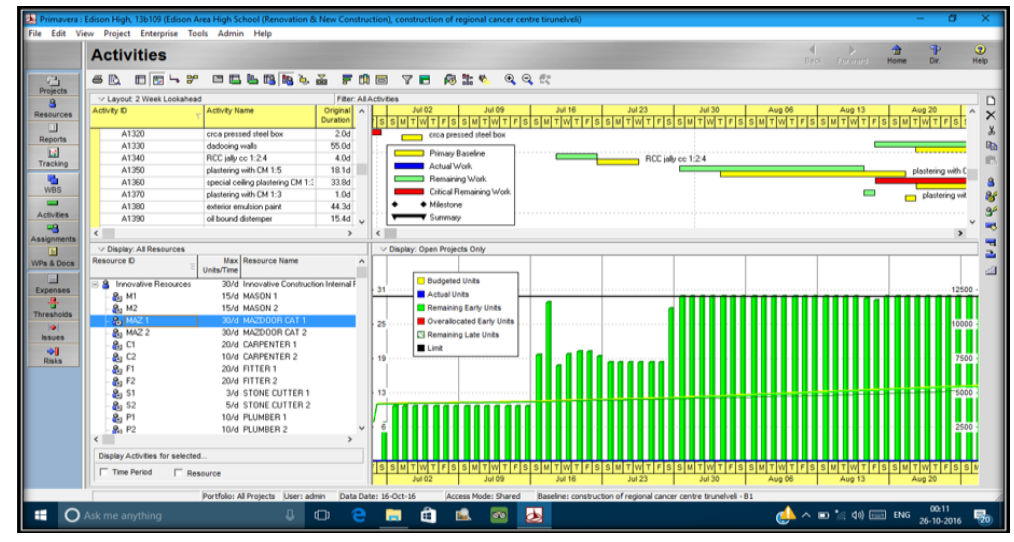

Figure 6 -Resource Histogram for Mazdoor category-1 (After leveling)

Similarly, then Snippet of Resource Histogram of painter $1^{\text {st }}$ class before and after levelling from primavera p6 is depicted below in figure7 \&figure 8 respectively. The histogram shown below gives the information about the quantity of Painter $1^{\text {st }}$ class, the contractor could afford to carry out the work . But it could also be seen from the red bars in the histogram, showing need for over allocation in order to complete the project within projected duration.But, as these many quantity of painter couldn't be possibly hired to work due to constraints and so there is need for optimisation, Primavera p6 serves the purpose in a better way.

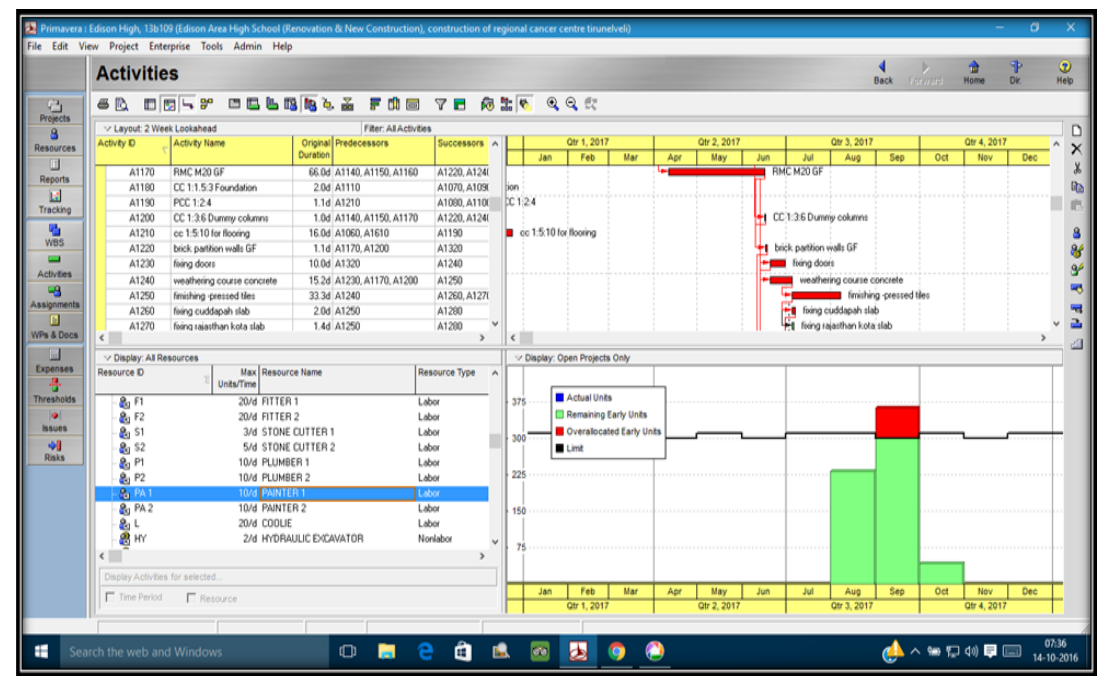

Figure 7 -Resource Histogram for painter $1^{\text {st }}$ class (Before leveling) 


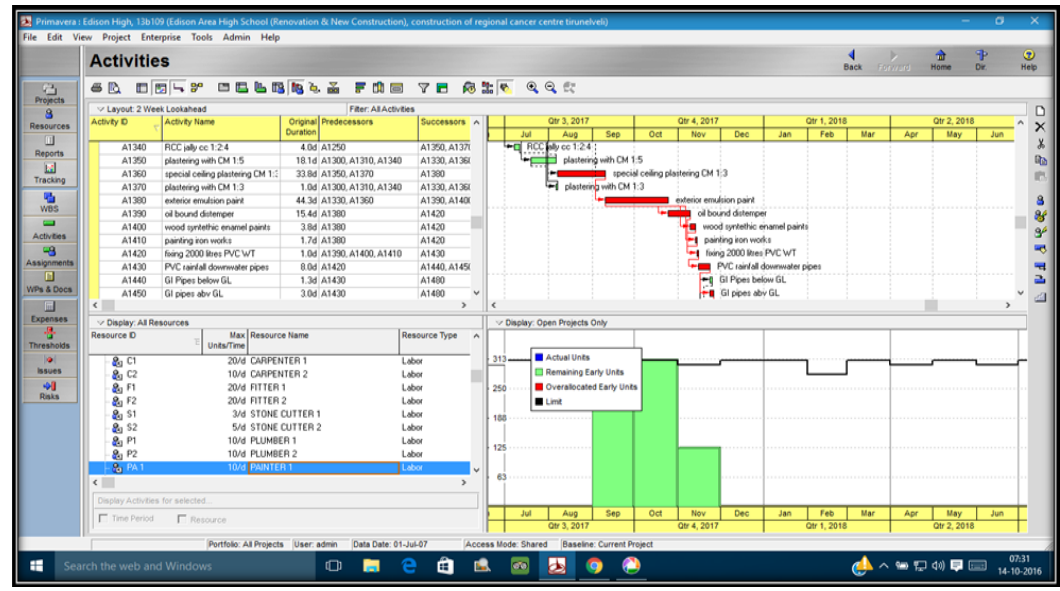

Figure 8 -Resource Histogram for painter $1^{\text {st }}$ class (After leveling)

Similarly, a considerable reduction in peak demand of all the resources can be effected by performing resource levelling. As a result of reduction of peak demand of all the resources, smoothing and levelling of labour resources would also lead to minimization of wastage of man-days, indeed the minimization of wastage of project cost . Wastage reduction in percentage for individual labour resource has been shown below in table 2 .

Table-2 Wastage Reduction Table

\begin{tabular}{|l|l|l|l|l|l|}
\hline S.no & Resources & Budgeted units & $\begin{array}{l}\text { wastage of } \\
\text { man-days }\end{array}$ & reduced cost( rs.) & $\begin{array}{l}\text { \% reduction in } \\
\text { labour cost }\end{array}$ \\
\hline 1 & Stone cutter $1^{\text {st }}$ class & 178 & 66 & 22902 & $0.3 \%$ \\
\hline 2 & Painter $1^{\text {st }}$ class & 1203 & 567 & 204687 & $2.52 \%$ \\
\hline 3 & Mazdoor category-1 & 7687 & 876 & 247032 & $3.04 \%$ \\
\hline 4 & Mazdoor category-2 & 4187 & 334 & 85300 & $1.05 \%$ \\
\hline 5 & All other resources & - & - & 74983 & $1 \%$ \\
\hline
\end{tabular}

The impact of Resource Optimisation on Project Cost and Duration on the total project has been depicted in below in Table 3.

Table-3 Summary of Resource Optimization

\begin{tabular}{|l|l|l|l|l|}
\hline project & $\begin{array}{l}\text { duration } \\
\text { (days) }\end{array}$ & $\begin{array}{l}\text { labour cost } \\
\text { (rs.) (in Lakhs) }\end{array}$ & $\begin{array}{l}\text { overall cost } \\
\text { (\% reduction) }\end{array}$ & $\begin{array}{l}\text { hike in } \\
\text { duration }\end{array}$ \\
\hline As per TENDER schedule & 420 & 85.58 & - & - \\
\hline $\begin{array}{l}\text { As per our schedule } \\
\text { (After RESOURCE SMOOTHING) }\end{array}$ & 370 & 81.32 & $1.02 \%$ & Fixed \\
\hline $\begin{array}{l}\text { As per our schedule } \\
\text { (After RESOURCE } \\
\text { LEVELLING) }\end{array}$ & 437 & 75.21 & $2.49 \%$ & Extended by 67 days \\
\hline
\end{tabular}

\section{Conclusion}

The initial schedule without resource optimization needs to be revised since there are over-allocations in the resources that have been used on the site. The resource idling is thus rectified by resource balancing on Primavera p6. The schedule may be initially optimized by resource smoothing and further optimised by carrying out resource levelling. The durations of the activities increase due to Resource Levelling but this step needs to be taken in order to resolve over-allocation of the resources present within a given firm. Certain changes can be made in the softwares such as Microsoft Project and Oracle Primavera wherein, activities consuming the same resource would not be allocated in parallel. 


\section{Acknowledgement}

I take this opportunity to express my sincere and heartfelt thanks to Dr.G.CHITRA, Associate Professor, Department of Civil Engineering for her valuable advice and inspiring guidance which has played a vital role in carrying out this investigation.I express my sincere thanks and gratitude to Dr.V.ABHAI KUMAR, Principal, Thiagarajar College of Engineering for providing all necessary facilities for completing this thesis work. I express my sincere thanks and gratitude to Dr.B.SIVAGURUNATHAN ,Head of the Civil Engineering Department, for always being with us under tough situations and providing full support for us to complete this thesis successfully. I sincerely thank the faculty of Civil engineering, Thiagarajar College of Engineering for their valuable advices. I also express my sincere thanks to all who have directly and indirectly assisted us in completing the work. I also express our sincere thanks to our friends for extending their co- operation and help during this work.

\section{VIGNESH V}

\section{References}

[1]. A Guide to the Project Management Body of Knowledge (PMBOK Guide). (2013). PMI.

[2]. B. S. K. Reddy, SK. Nagaraju and MD. Salman (2015) 'A Study on Optimization of Resources for Multiple Projects by using Primavera', Journal of Engineering Science and Technology Vol. 10, No. 2 PP. 235 - 248 @ School of Engineering, Taylor's University

[3]. ELIYAHU M. GOLDRATT (1990) 'What is this thing called theory of constraints and how should it be implemented?' North River Press, Croton-on-Hudson, N.Y.

[4]. Anuj Dubey (2015) 'Resource Levelling for a Construction Project', IOSR Journal of Mechanical and Civil Engineering (IOSRJMCE) e- ISSN: 2278-1684, p-ISSN: 2320-334X, Volume 12, Issue 4 Ver. IV (Jul. - Aug. 2015), PP.05-11, www.iosrjournals.org

[5]. Archibald, R. D. and Villoria, R. L. (1966) 'Network-based management systems (PERT/CPM)', Wiley, New York.

[6]. Gido, J. and Clements, J. P. (2003) 'Successful project management', Thomson/South-Western, Mason, Ohio.

[7]. John C. Hildreth and Brian P. Munoz (2005) 'An Introduction to the Management Principles of Scheduling', A report presented to the Virginia Department of Transportation and the VDOT-VT Partnership for Project Scheduling Advisory Board.

[8]. Maroto, C., Tormos, P., \& Lova, A. (1998). "The evolution of software quality in project scheduling”. (W. J, Ed.) Project scheduling - recent models, algorithms and applications .

[9]. Steiness, K. (2014, August 26). "Resource Leveling Best Practices". Retrieved July 3, 2015, from MPUG: http://www.mpug.com/articles/resource-leveling-best-practices/

[10]. Tran, H.-H., \& Hoang, N.-D. "A Novel Resource-Leveling Approach for Construction Project Based on Differential Evolution”.

[11]. Winter, R. (2006). "Proper Implementation of Resource Leveling. Ron Winter Consulting".

[12]. Yang, B., Geunes, J., \& O' Brien, W. J. (2011, April). "Resource-Constrained Project Scheduling: Past Work and New Directions". 